5. Kilo C, Miller Ph, Williamson JR (1980) The crux of the UGDP. Spurious results and biologically inappropriate data analysis. Diabetologia 18: 179-185

6. Knowler WC, Sartor G, Melander A, Scherstein B (1997) Glucose tolerance and mortality, including a substudy of tolbutamid treatment. Diabetologia 40: 680-686

7. Turner RC, Millns H, Holmann RR (1997) Coronary heart disease and risk factors in NIDDM - experience from the United Kingdom Prospective Diabetes Study. Diabetologia 40:S121-S122
8. Shimabukura M, Nagamine F, Murakami K, Oshiro K, Mimura G (1994) Chronic gliclazide treatment affects basal and post-ischemic cardiac function in diabetic rats. Gen Pharmacol 25: 697-704

9. McDonagh PF, Hokama JY, Copeland JG, Reynolds JM (1997) The blood contribution to early myocardial reperfusion injury is amplified in diabetes: Diabetes 46: 1859-1867

10. Leibowitz G, Cerasi E (1996) Sulphonylurea treatment of NIDDM patients with cardiovascular disease: a mixed blessing ? Diabetologia 39: 503-514

\section{Possible risk of sulphonylureas in the treatment of non-insulin-dependent diabetes mellitus and coronary artery disease}

Dear Sir,

We are grateful for the possibility to expand further on our above referenced hypothesis [1] in response to the letter by Dr. Fasching.

Even though the relevance of the results of the UGDP as devastating for sulphonylureas and biguanides as they were - may have been debatable [2], there has never been a study to rule out any cardiotoxic effect of sulphonylurea therapy. Recent findings in animals and humans have provided a pathophysiological plausibility for our hypothesis, as sulphonylureas appear to aggravate the hypoxaemic damage to the myocardium in the case of coronary occlusion or artery disease $[1,3,4,5]$. In fact, such a pathophysiological scenario fits well with the observation that the alleged cardiotoxic effect of sulphonylureas appears to exert itself in an increased lethality of myocardial (re-) infarctions or cardiac death rates, rather than by increasing cardiac events or the incidence of cardiovascular morbidity $[1,7]$. In this situation, appropriate studies directed at efficacy and safety of sulphonylurea drugs have been demanded recently $[5,6,8]$.

The UKPDS is certainly not going to be helpful in this context, as patients with clinically relevant coronary artery disease have been excluded during the recruitment process: the entire cohort included only $3 \%$ patients with a history of angina pectoris (excluding those with present angina), $2 \%$ with a history of myocardial infarction (prior to 1 year before recruitment) and patients with heart failure were excluded [9]. Furthermore, the study does not have the statistical power to rule out clinically relevant differences concerning cardiovascular morbidity and mortality between the four treatment arms represented under Intensive Therapy [9, 10].

Finally, we agree with Dr. Fasching that sulphonylureas must not be judged as a drug class; rather more every sulphonylurea drug needs to be studied individually for its effectivity and safety vis-à-vis the relevant endpoints for Type II diabetes mellitus, i.e. cardiovascular morbidity and mortality - rather than being limited to surrogate markers [11]. The fact that any such positive evidence has never been demonstrated for this (and any other) oral antidiabetic drug is most disturbing and, indeed, should alarm the "doctors and frighten their patients".

In our opinion, the - albeit incomplete - evidence implementing a cardiotoxic effect of sulphonylurea drugs has be-

Corresponding author: Professor M. Berger, Klinik für Stoffwechselkrankeiten und Ernährung (WHO Collaborating Center for Diabetes), Heinrich-Heine Universität Düsseldorf, Moorenstraße 5, D-40025 Düsseldorf, Germany come substantial enough to shift the burden of proof on to those who are still using sulphonylurea drugs in Type II diabetic patients with coronary heart disease to document that this is actually safe.

Yours sincerely,

M. Berger, I. Mühlhauser, PT Sawicki

\section{References}

1. Mühlhauser I, Sawicki PT, Berger M (1997) Possible risk of sulphonylureas in the treatment of non-insulin-dependent diabetes mellitus and coronary artery disease. Diabetologia 40: $1492-1493$

2. Kolata GB (1979) Controversy over study of diabetes drugs continues for nearly a decade. Science 203: 986-990; with correspondence section: Diabetes Drugs: Clinical Trial by Prout TE, Knatterud GL, Meinert CG and Goldner MG and Meier P (1979) Science 204: 362-365

3. Cleveland JC; Meldrum DR, Cain BS, BanerjeenbA, Harken AH (1997) Oral sulphonylurea hypoglycemic agents prevent ischaemic preconditioning in human myocardium. Circulation 96: 29-32

4. Tomai F, Crea F, Gaspardone A et al. (1994) Ischemic preconditioning during coronary angioplasty is prevented by glibenclamide, a selective ATP-sensitive $\mathrm{K}+$ channel blocker. Circulation 90: 700-705

5. Engler RL, Yellon DM (1996) Sulphonylurea $\mathrm{K}_{\text {ATP }}$ blockade in Type II diabetes and preconditioning in cardiovascular disease. Time for reconsideration. Circulation 94: 2297-2301

6. Berger M (1993) Neue Gesichtspunkte zur Kontroverse um die Sulphonylharnstoffe. Diabetes und Stoffwechsel 2: 110-111 (abst.)

7. University Group Diabetes Program (1976) A study of the effects of hypoglycemic agents on vascular complications in patients with adult-onset diabetes. VI. Supplementary report on nonfatal events treated with tolbutamide. Diabetes 25: 1129-1152

8. Hofmann D, Opie LH (1993) Potassium channel blockade and acute myocardial infarction: implications for management of the non-insulin requiring diabetic patients. European Heart Journal 14: 1585-1589

9. UK Prospective Diabetes Study Group (1991) UK Prospective Diabetes Study (UKPDS). VIII. Study design, process and performance. Diabetologia 34: 877-890

10. Turner R, Cull C, Holman R (1996) United Kingdom Prospective Diabetes Study 17: A 9-year update of a randomized, controlled trial on the effect of improved metabolic control on complications in non-insulin-dependent diabetes mellitus. Annals Intern Med 124 (1 pt. 2):136-145

11. Mühlhauser I, Berger M (1996) Surrogat Marker Trugschlüsse. Dt. Ärztebl. 93:A-3280-A-3283 